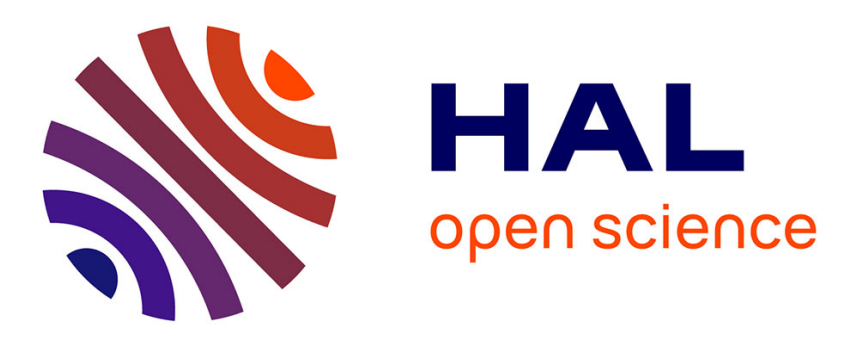

\title{
Femtosecond photoswitching dynamics and microsecond thermal conversion driven by laser heating in FeIII spin-crossover solids.
}

\author{
Roman Bertoni, Maciej Lorenc, A. Tissot, M.L. Boillot, Eric Collet
}

\section{- To cite this version:}

Roman Bertoni, Maciej Lorenc, A. Tissot, M.L. Boillot, Eric Collet. Femtosecond photoswitching dynamics and microsecond thermal conversion driven by laser heating in FeIII spin-crossover solids.. Coordination Chemistry Reviews, 2015, 282-283, pp.66-76. 10.1016/j.ccr.2014.05.024 . hal-01005418

HAL Id: hal-01005418

https://hal-univ-rennes1.archives-ouvertes.fr/hal-01005418

Submitted on 12 Jun 2014

HAL is a multi-disciplinary open access archive for the deposit and dissemination of scientific research documents, whether they are published or not. The documents may come from teaching and research institutions in France or abroad, or from public or private research centers.
L'archive ouverte pluridisciplinaire HAL, est destinée au dépôt et à la diffusion de documents scientifiques de niveau recherche, publiés ou non, émanant des établissements d'enseignement et de recherche français ou étrangers, des laboratoires publics ou privés. 
Edited May 24

\section{Femtosecond photoswitching dynamics and microsecond thermal conversion driven by laser heating in Fe"l' spin-crossover solids.}

R. Bertoni, ${ }^{a}$ M. Lorenc, ${ }^{a}$ A. Tissot, ${ }^{b}$ M.-L. Boillot, ${ }^{b}$ E. Collet ${ }^{a,{ }^{*}}$

anstitut de Physique de Rennes, UMR UR1-CNRS 6251, Université Rennes 1, 35042 Rennes, France

${ }^{\mathrm{b}}$ Institut de Chimie Moléculaire et des Matériaux d'Orsay, UMR-CNRS 8182, Université Paris-Sud, Orsay, France.

*Corresponding author: Tel.: +33 223236532Fax: +33223236717.

E-mail address : eric.collet@univ-rennes1.fr (E. Collet)

\section{Contents}

1 Introduction

2 The different thermal spin crossover of the investigated Fe(III) compounds 3Ultrafast photoswitching

3.1 Results

3.2 Discussion

4Spin-state switching driven by lattice expansion and heating

4.1 Results

4.2 Discussion

4.3 Comparison between strongly and weakly cooperative crystals

5 Conclusion

6 Experimental section

Acknowledgements

References

\section{Abstract}

In this paper we review time-resolved studies of ultrafast light-induced spin-state switching, triggered by a femtosecond laser flash,and the following out-of-equilibrium dynamics in Fe"I spincrossover crystals. The out-of-equilibrium dynamics involves several steps, resulting fromthe ultrafast molecular photoswitchingof low-spin (LS) to high-spin (HS) states in solids. First, the transient HS state is reached within 200 femtoseconds, and mayrapidly decayinto the stable LS state of the system. A second process at longer delay,associated with volume expansion, drives additional conversion to the HS state during the so-called elastic step occurring at nanosecond time scale. Finally, the laser heating process induces a temperature jump in the crystal that may result in a significant thermal population of the HS state on microsecond time scale. The photoswitching mechanism is of local nature and has linear dependenceon the excitation fluence, whereas the heating effect can macroscopically perturb the LS/HS equilibrium. We discuss similarities and differences between photoswitching dynamics in solution and in different crystals for which the thermal spin conversion is of more or less pronounced cooperative nature. 
Edited May 24

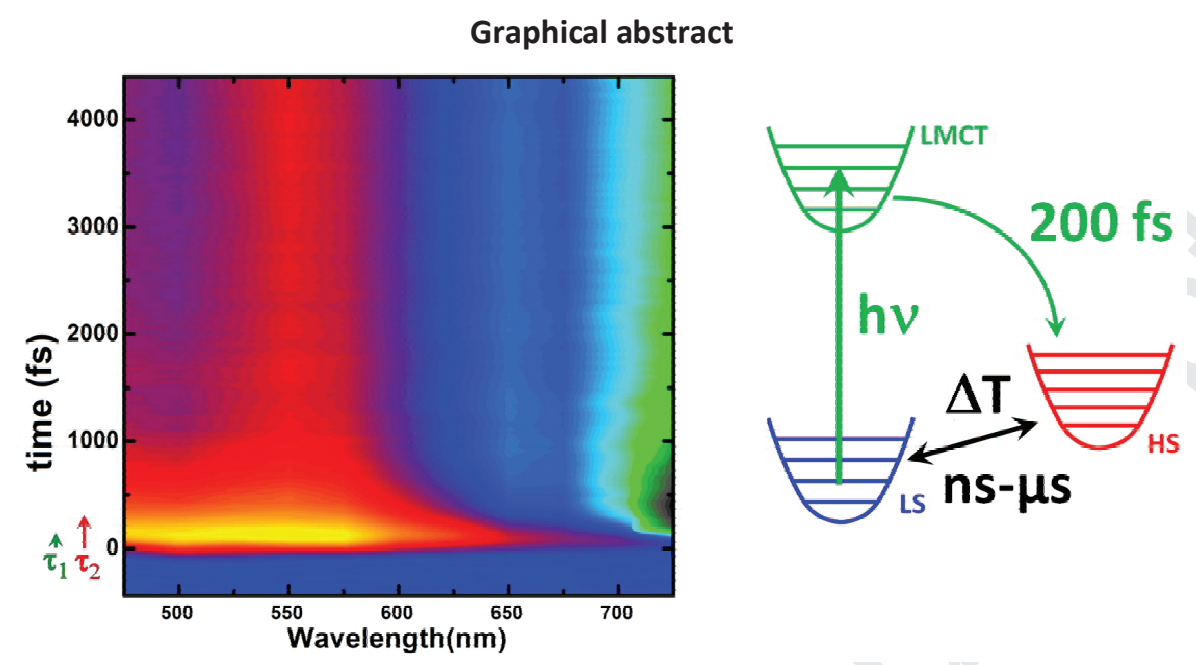

\section{Highlights}

Ultrafast spectroscopy reveals spin-state photo-switching in molecular crystals

Keywords: Spin-crossover; Intersystem crossing; Radiationless relaxation; femtosecond spectroscopy; ultrafast spectroscopy 
Edited May 24

\section{Introduction}

Bridging the gap between molecular photoswitchingin solution $[1,2,3]$ and photoinduced phase transition in thesolid state[4,5] is important for the development of photo-active materials. Indeed, bistable molecules in solution exhibit a wealth of light-induced transformations, which may give rise to inter- or intra-molecular chemical reactions[6], electron transfer $[7,8]$ or changes of the molecular states[9,10,11].In molecule-based solids,light-induced phenomena are important for driving a material between different statesassociated with different macroscopic physical properties[12,13,14,15,16,17]. Femtosecond laser pulses are widely regarded as the most likely source for switching molecular solids on ultrafast timescale[18,19,20,21,22,23,24,25].Among the latters, spin-crossover compounds (SCO) are prototypes of systemsshowing molecular bistability in the solid state, which may be converted from low-spin (LS) to high-spin (HS) states under various external perturbations. In these materials, the photoswitching under weak continuous light irradiationat low temperature was extensively studied [26,27], and few reports discussed the relaxation mechanism after nanosecond laserexcitation[28,29].Regarding the photoswitching dynamics of the SCO molecule itself, there exists arobust literature dealing with investigations on isolated SCO molecules in solution, using ultrafast optical, X-ray or Raman spectroscopies. Major developments by the groups of Chergui, McCusker,McGarvey, Hendrickson,Mathies, Schoenlein and others gave a comprehensive description of the subtle coupling between the changes of electronic states and the structural

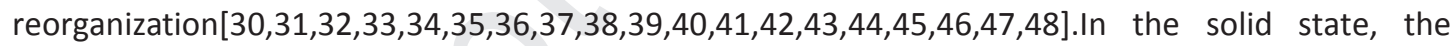
interaction between molecules can give rise to more complicated phenomena, such as the appearance of striped structures of bi-stable spin-crossover molecules in HS and LS states, of periodic [49] or aperiodic nature[50].The strong intermolecular coupling can also give rise to cooperativity and first-order phase transition[51] from purely LS to purely HS states with thermal hysteresis. Recently, nanosecond laser excitation demonstrated the possibility to generate LS to HS transition inside thermal hysteresis loop[29,52].

Ultrafast investigations of photo-transformations in crystals were later carried out for Light Induced Excited-Spin State Trapping (LIESST)[53] and more recently for reverse LIESST[54], and it was revealed that the crystal response to femtosecond excitation is a multi-step process[21].By usingultrafast optical spectroscopy and time-resolved photocrystallography,we provided a comprehensive account ofthe sequence of events schematically represented in Fig. 1.The typical time-resolved optical data shown in Fig. 1aindicatea three stepsdynamic[55,56,57,58,59,60], as the relative change of transmitted light intensity $\Delta \mathrm{l} / \mathrm{I}$ increases with the HS fraction. First, the absorption 
Edited May 24

of light at the molecular level locally switches a small fraction $\Delta X_{H S}{ }^{h v} \approx 1 \%$ ofmolecules on the subpicosecond timescale from LS to HS state. The fraction of HS molecules remains unchanged over to 1-10 ns as during this interval, but every photo-excited molecule releases heat through electronphonon coupling and then phonon-phonon relaxation processes. This local process leads to lattice expansion shown in Fig.1b, observed by time-resolved x-ray diffraction $[21,55,57,58]$, which occurs $\approx 50$ ns after photo-excitation. During this elastic step, the second step in sequence, the fraction of HS molecules increases, as a result of the internal pressure due to lattice expansion[56,60]. However, this expansion is not instantaneous but rather limited by the propagation of elastic strain in the crystal (typically at the speed of sound). Finally, the last step resulting from the heating of the lattice by the laser flash is the thermal population of the HS state which occurs on the $\mu$ s regime. This heating is associated with an important increase of the Debye-Waller factor observed by $x$-ray diffraction (Fig. 1c).
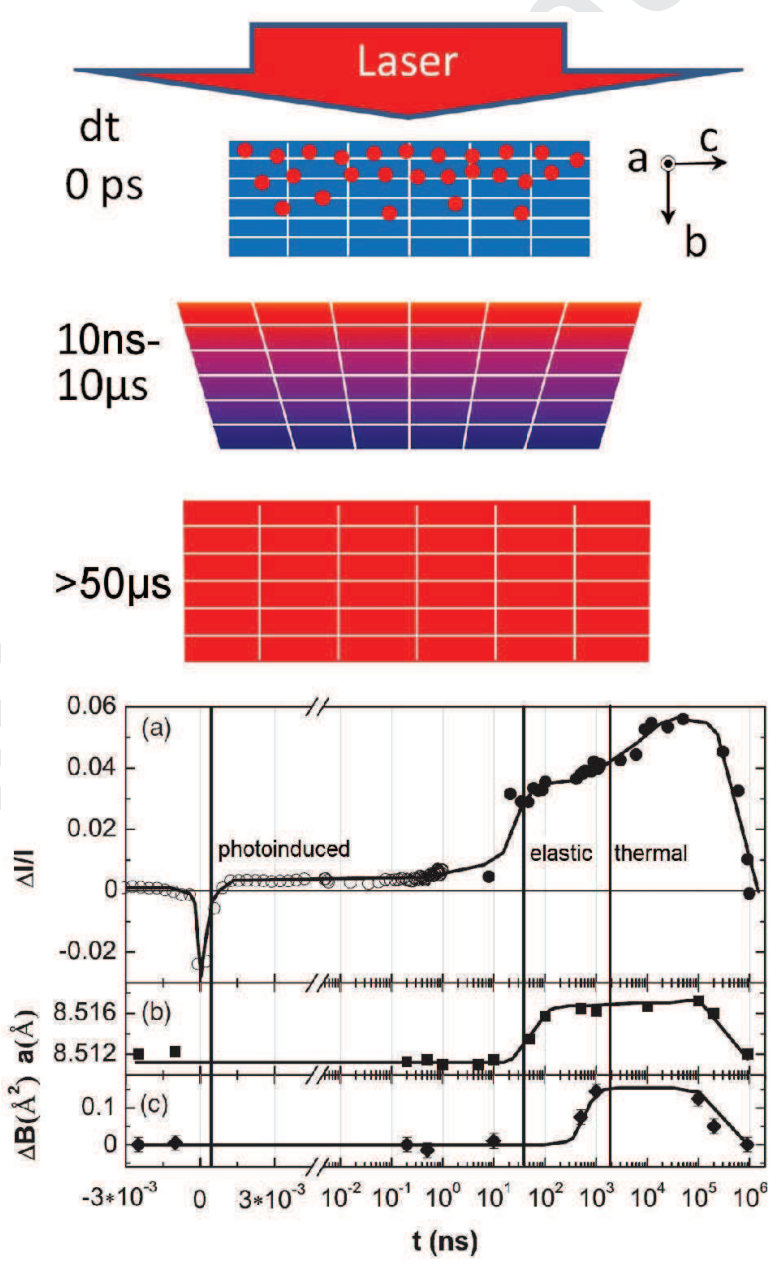

Fig. 1. Top: Schematic drawing of the dynamics. The laser deposits energy on photo-excited molecules (red dots) of the crystal at $\mathrm{dt}=0 \mathrm{ps}$. The gradient of deposited energy results in an inhomogeneous lattice expansion in the $10 \mathrm{~ns}-10 \mu \mathrm{s}$ time window. At $50 \mu \mathrm{s}$, the temperature is homogenized over the crystal and the 
Edited May 24

heating effect results in thermal population of the HS state. (a) Differential intensity of transmitted probe light $(\Delta \mathrm{I} / \mathrm{I})$ measured at $600 \mathrm{~nm}$ on a single crystal of (TPA)Fe(TCC)]PF ${ }_{6}$ after femtosecond excitation at $800 \mathrm{~nm}$ at 200 K. (b), (c) Time-resolved x-ray diffraction experimental data: lattice parameter a (b) and variation of DebyeWaller factor $B$ between $d t<0$ and $d t>0$ (c). Solid lines are drawn to guide the eyes. These figures werereproduced from ref. $[55,58]$, with permission of the copyright holders.

Those studies dealt with non-cooperative materials undergoing thermal conversion of crossover type [61]. One may wonder if the abovementioned multi-step dynamics is still valid for cooperative materials undergoing first-order phase transition, and how the response differs in the time domain with regard to non-cooperative systems. Here we present a review of the results obtained in four Fe(III) spin-crossover complexes (Fig. 2). The two first samples are [Fe(3-MeOSalEen) ${ }_{2} \mathrm{PF}_{6}$ single crystals (1), nano-crystals (2), H-3-MeO-SalEen being the condensation product of 3-methoxy-substituted salicylaldehyde and N-ethyl-ethylenediamine. The two others are

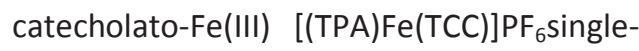
crystals, where TPA = tris(2-pyridylmethyl)amine and $\mathrm{H}_{2} \mathrm{TCC}=3,4,5,6$ tetrachlorocatecholate, of the monoclinic (3) and orthorhombic modifications (4) [61]. As shown in Fig. 2, (1) undergoes a firstorder spin transition with small hysteresis, whereas (2), (3) and (4) undergo more gradual conversions. We also present complementary results to those already reported for (1).

\section{$\left[\mathrm{Fe}(3-\mathrm{MeO}-\mathrm{SalEen})_{2}\right]^{+} \quad[\mathrm{Fe}(\mathrm{TPA})(\mathrm{TCC})]^{+}$}

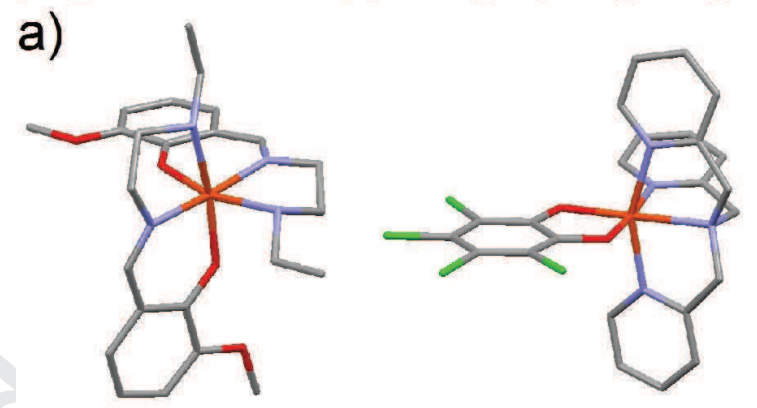

b)

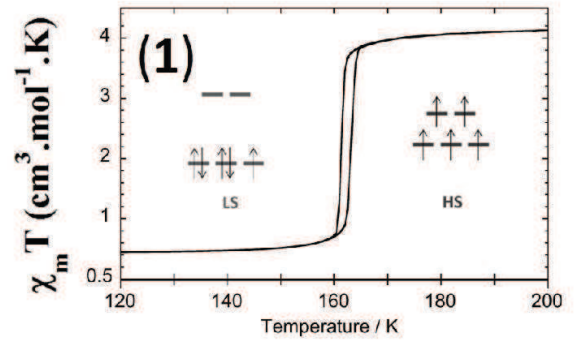

Fig. 2. The $\left[\mathrm{Fe}(3-\mathrm{MeO}-\mathrm{SalEen})_{2}\right]^{+}$and

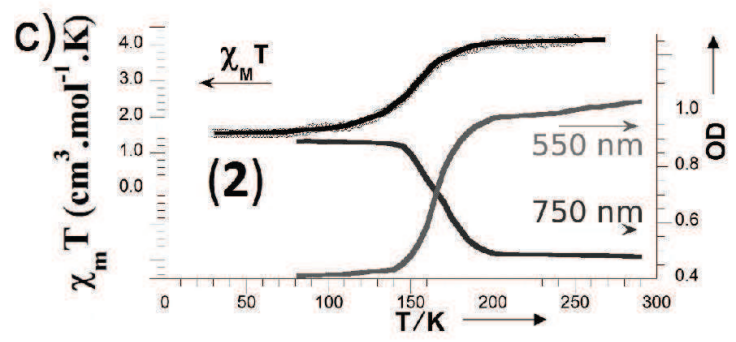

[(TPA)Fe(TCC) $]^{+}$cations. $\chi_{M}{ }^{\top}$ versus $T$ plots are given for single crystals $(\mathbf{1}$, a) and nanocrystals $\left(2\right.$, c) of $\left[\mathrm{Fe}(3-\mathrm{MeO}-\mathrm{SalEen})_{2}\right] \mathrm{PF}_{6}$ and for the monoclinic $(3, d)$ and orthorhombic $(4, d)$ forms of $[(T P A) F e(T C C)] \mathrm{PF}_{6}$. Figures were reproduced

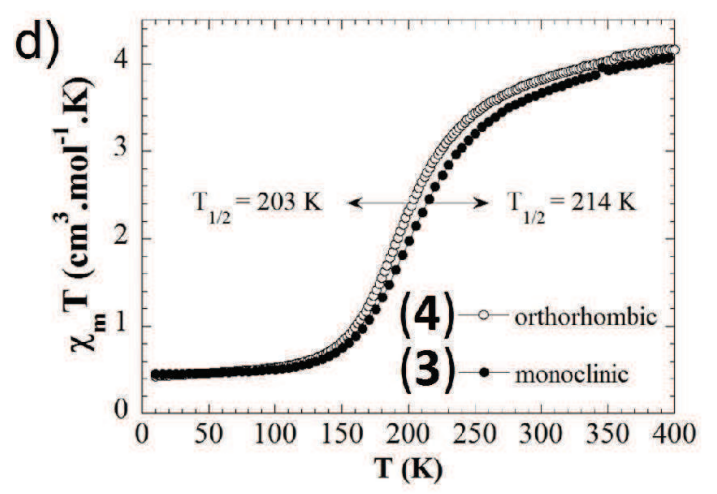


Edited May 24

from ref. $[53,61,62]$, with permission of the copyright holders. 
Edited May 24

\section{The different thermal spin conversion of the investigatedFe(III) compounds}

Single crystals of (1) are shown in Fig. 3a.This complex was initially synthesized by Hendrickson group[63], and its crystalline form undergoes a first-order transition between LS (S=1/2) and $\mathrm{HS}(\mathrm{S}=5 / 2)$ states around $162 \mathrm{~K}[62]$. It is characterized by a discontinuous evolution of the $\chi_{M}$ Tvs. T curve $\left(\chi_{M}=\right.$ molar magnetic susceptibility, $T=$ temperature $)$ in relation with the spin-state switching (Fig. 2b).This discontinuous conversion, associated with a narrow thermal hysteresis, is the signature of strongly cooperative process.A detailed study of the phase transition at thermal equilibrium and of the associated structural changes involved is presented in ref [62].

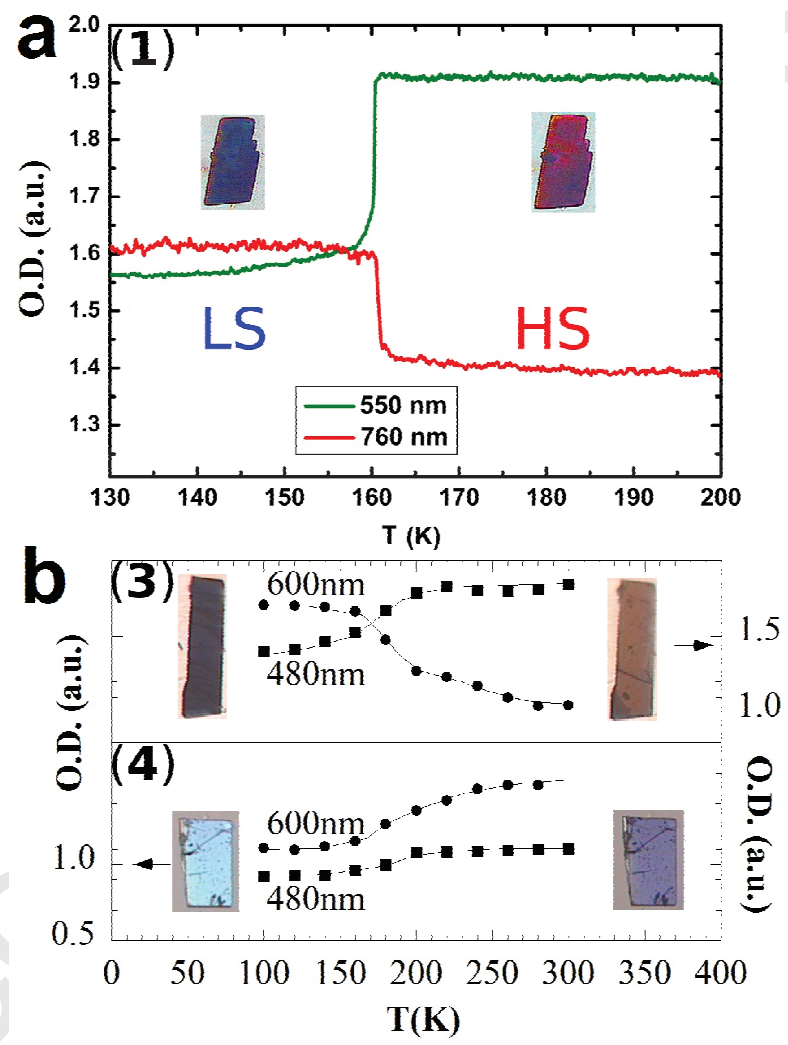

Fig. 3. Temperature dependence of the optical density at 550 and $760 \mathrm{~nm}$ fora $20 \mu \mathrm{m}$ thin single crystal of $(\mathbf{1}$, a) and at 480 and $600 \mathrm{~nm}$ for single crystals of $(3, \mathbf{b})$ and $(\mathbf{4}, \mathbf{b})$. Photographs were made in pure LS and HS states.Figure ?a b was reproduced from ref. [61], with permission of the copyright holders. 


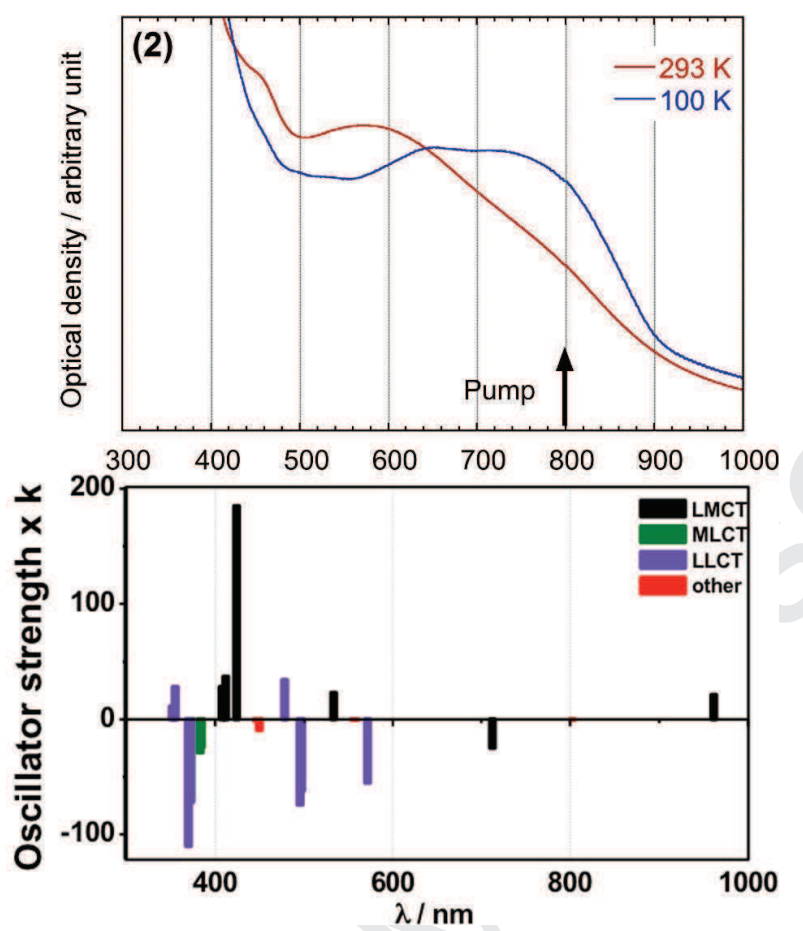

Fig. 4. Optical spectra of (1) recorded as a function of temperature. TheTD-DFT calculations [64] reported for $\left[\mathrm{Fe}^{\text {III }}(\text { pap })_{2}\right]^{+}$(H-pap, tridentate $\left[\mathrm{N}_{2} \mathrm{O}\right.$ ] Schiff-base), a closeanalogue of $(\mathbf{1}, \mathbf{2})$ provide the typicalenergies and oscillatorstrengths (for shake of clarity, $k=(-1)^{n} \times 10^{3}$ ) of LS $(n=1)$ and HS $(n=0)$ electronic absorptions of a Fe"ll Schiff-base complex. The labelscorrespond with charge transfer (CT) electronic transitions involving ligand (L), metal (M) centeredfrontierorbitals (for instance ligand-tometal charge transfer, LMCT) while the 'other' label means ddtransitions.

The single-crystal material (1) shows thermochromism from dark blue to orange, characterized by the discontinuous change of optical density (OD), shown in Fig. 3a at 550 and 760 $\mathrm{nm}$, associated with thediscontinuous thermal transition from pure LS to pure HS statearound $162 \mathrm{~K}$. Optical measurements performed on nanocrystals of this compound (2)processed intransparent polymeric films revealed the associated spectral changes (Fig. 4). It corresponds with an increase of OD on HS LMCT (ligand to metal charge transfer) band centered around $550 \mathrm{~nm}$ and a decrease on another LMCT band centered around $750 \mathrm{~nm}$ [53], an assignment confirmed by the theoretical works by Cano and Ando on the same class of compound. The related data (energy and oscillator strength) in Fig. 4 also show the distinct Charge-Transfer (CT) components between Ligand (L) and Metal (M): LMCT at low energy, LLCTand MLCT at higher energy, resulting in the NIR-VIS absorption features (at c.a. 800, 550 and $400 \mathrm{~nm})[64,65]$. Sample(2), anano-crystals assembly of the Fe(III) complex [Fe(3MeO-SalEen) ${ }_{2} \mathrm{PF}_{6}$ in a polymeric matrix, undergoes a thermal spin-crossover between LS and HS states centered at $\mathrm{T}_{1 / 2}=156 \mathrm{~K}$, as indicated by the change inmagnetic susceptibility and color (Fig. 2c, Fig 3a). It shows a loss of first-order character in comparison with macroscopic single crystals. As the 
Edited May 24

nanocrystals are embedded in a PVP film, this effect is attributed to particle-matrix interactions [66]. The temperature dependence of the $\chi_{M} T$ product for (3) and (4) are typical forgradual thermal crossover from low temperature $S=1 / 2(L S)$ to high temperature $S=5 / 2(H S)$ states (Fig. 2d). The characteristic temperaturescorresponding to $50 \%$ conversionare $T_{1 / 2} \approx 214 \mathrm{~K}$ for (3) and $\approx 203 \mathrm{~K}$ for (4). This shift results from the different molecular packing between the polymorphs (3) and (4). Their optical properties also differ during the LS to HS conversion: (3) changes from dark violet to orange whereas (4) changes from light blue to dark blue (Fig. 3b) and theoptical density at $600 \mathrm{~nm}$ decreases for (3) and increases for (4).

These changes of OD, commonly used for monitoring the thermal evolution of the HS population, are used here for tracking the evolution of the fraction of molecules in the HS state in time by using the transient absorption pump-probe method described in ref [55] (experimental section hereafter).

\section{Ultrafast photoswitching}

We performed ultrafast studies of photo-switching of these materials by exciting with fs laser pulse these compounds on the LMCT band related to the LSstate, that is located on the low energy side ofabsorption bands as established (i) from the relative LS and HS absorption intensities, (ii) bycomparison with oscillator strength calculations inan analogue of (2) (Fig 4).The typical timeresolved data shown in Fig. 1 and obtained for (3), evidence the sub-picosecond timescale from LS to HS statephotoswitching. In the section below, we analyze in detail the sub-picosecond photoswitching process for the different Fe(III) compounds.

\subsection{Results}

We compare in Fig. 5new results of the photoswitching dynamics for (1), for which previous fs studies indicated changes of optical transmission on $200 \mathrm{fs}$ time scale [62], with the results already reported for (2), (3) and (4).For (1), the evolution of $O D, \triangle O D$, following fs laser excitation of (1)indicates two main steps. A transient peak appears immediately after excitation and $\triangle O D$ settles ontoa plateau in the second step on a timescale shorter than 1ps. As for the spectroscopic study performed on(2) (Fig 5b, [53]) $\triangle O D$ increases at $550 \mathrm{~nm}$ and decreases at $760 \mathrm{~nm}$ for single crystals(Fig 5a), whichis a direct signature of HS state formation, in good agreement with changes of $O D$ observed at thermal equilibrium from the LS to HS states (Fig. 3a).For (3) and (4) similar 2-step processes are observed with a dynamical process complete at the ps timescale (Fig. 5c). In these low symmetry crystals, the OD strongly depends on the direction of light polarization with respect to crystalline axis, as discussed in details for (3) and (4) [61]. This is also the case for (1)but we were not 
Edited May 24

able to perform a polarization analysisbecause of the too high extinction coefficient of single crystals. Therefore, we only measured with the polarization allowing maximal transmitted signal.
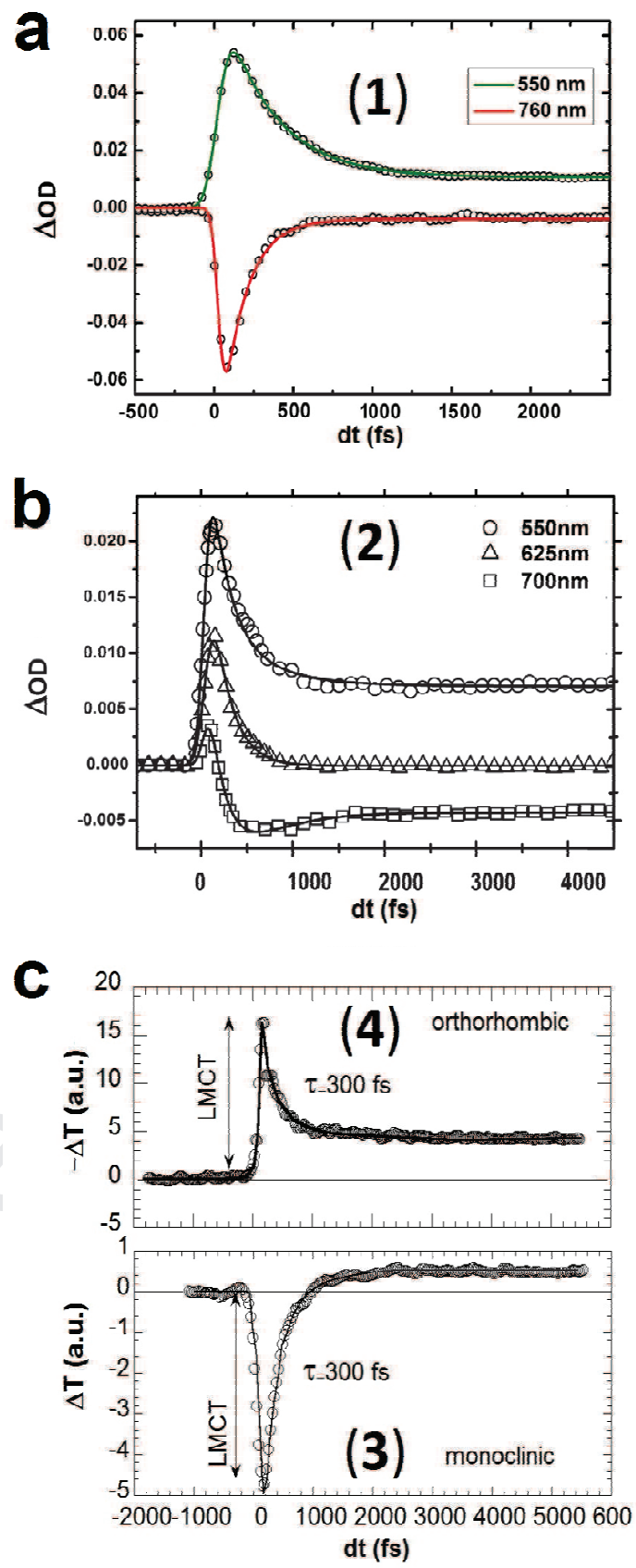

Fig.5. Kinetic traces of $\triangle O D$ obtained by two-color pump-probe experiment for $(\mathbf{1}, \mathbf{a})$ and $(\mathbf{2}, \mathbf{b})$ and of the increase of transmission $\Delta T$ for $(\mathbf{3}, \mathbf{c})$ and decrease of transmission $-\Delta T$ for $(\mathbf{4}, \mathbf{c})$. Fits with the monoexponential model (solid lines) give $\tau=330 \pm 40 \mathrm{fs}$ at $550 \mathrm{~nm}$ and $\tau=180 \pm 40 \mathrm{fs}$ at $760 \mathrm{~nm}$ for (1), $\tau=350 \pm 40$ fs at $550 \mathrm{~nm}$ and $\tau=200 \pm 40 \mathrm{fs}$ at $625 \mathrm{~nm}$ for (2) $\tau=300 \pm 40 \mathrm{fs}$ at $600 \mathrm{~nm}$ for (3) and (4), Figures were reproduced from ref. $[53,58]$, with permission of the copyright holders. 
Edited May 24

\subsection{Discussion}

The two dimensional time-wavelength plot of $\triangle O D$ following femtosecond laser excitationis shown in Fig. 6 for (2) [53].Itprovides the spectroscopic signatures of the states involved in thetwo sub-pssteps. The transient absorption band which appearsimmediately after laser excitation, is characteristic of the excited electronic states. The plateau reached with a time constant shorter than one picosecond is associated with spectral features corresponding topositive $\triangle O D$ in VIS and negative $\triangle O D$ in NIR, revealing the formation of HS state in agreement with Fig. 4. The transient response recorded during the first $100 \mathrm{fs}$ differs significantly, with a broad and strong absorption band dominating the VIS-NIR spectrum, indicating that the observed transient species are neither LS nor HS. It was deduced from these observations(Fig. 6) that the HS formation mechanism involves a short-lived excited stateresulting from the population of the LMCT and other possible intermediate excited states (denoted INT, see below).
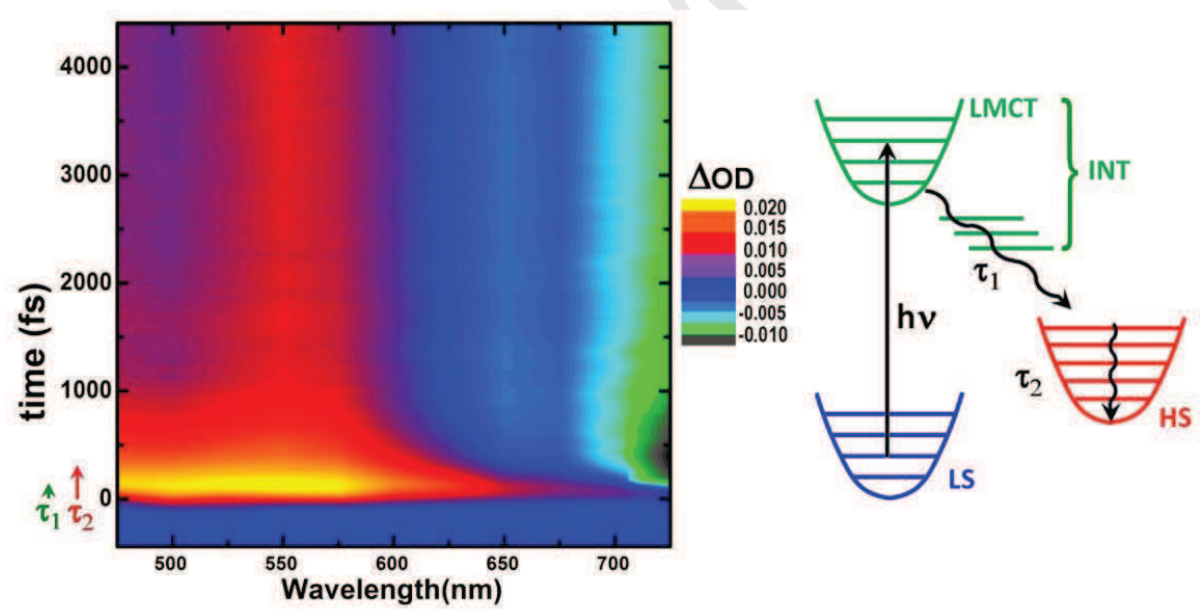

Fig. 6. 2D time-wavelength plot of $\triangle O D$ after femtosecond laser excitation for (2) and schematic representation of the photoswitching pathway with time constants $\tau_{1}$ for the relaxation of short-lived intermediate states (INT), and $\tau_{2}$ for the vibrationnal cooling of the photoinduced state. Figure was reproduced from ref. [53], with permission of the copyright holders.

In Fe(III) compounds the low-energy excitations of LS state, promote charge-transfer between the electronic configuration $L^{2} t_{2 g}{ }^{5} e_{g}{ }^{0}$ like (or more precisely $L^{2} d_{\pi}{ }^{5} d_{\sigma}{ }^{0}$ ), where $L$ refers to symmetryadapted and occupied molecular orbitals centered on ligands, and an electronic configuration $L^{1} t_{2 g}{ }^{6}$ $e_{g}^{0}$ like (or $L^{1} d_{\pi}^{6} d_{\sigma}^{0}$ ). Therefore, the femtosecond pump pulse leads to a LMCT Franck-Condon excited state that relaxes through intersystem crossing, and possibly via different intermediate states, to the 
Edited May 24

HS state (Scheme Fig 6). For single crystal, we could not perform broadband spectroscopy because of the high absorption in the VIS range, but data in Fig. 5aevidence the transient peak resulting from the instantaneous population of LMCT state. The simple model used here for reproducing the kinetics of this photoswitching from LS to HS states in single crystals only considers a global intermediate state corresponding to the fastdecay from the LMCT state to the final HS state. Therefore we describe the population of the HS state with a time constant $\tau$. For the fitting procedure, we convoluted this exponential decay with the Gaussian IRF of our experiment (140 fs) and we found $\tau=180 \pm 40 \mathrm{fs}$ for the $\triangle O D$ time trace at $760 \mathrm{~nm}$ in quite good agreement with $\tau=200 \pm 20 \mathrm{fs}$ reported for(2)[53]. For the $\triangle O D$ time trace at $550 \mathrm{~nm}$ we found a longer time constant $\tau=330 \pm 40 \mathrm{fs}$. This is due to the fact that the single exponential model used here is too simple for reproducing the kinetics of this photoswitching process. Indeed, it was shown in nanocrystalsthat the dynamics is better described over a broad spectral range with a bi-exponential model, for which a fixed time constant $\tau_{1}$ (of $200 \mathrm{fs}$ ) describes the population of theHS state by the depopulation of intermediate (INT) electronicstates and a longer time constant $\tau_{2}$ describes the vibrationnal cooling ofthe hot HS state, associated with a global spectral narrowing (Fig. 6). By analyzing the data in this way, both measurements on single crystals andnanocrystals indicated that the time traces of OD at $550 \mathrm{~nm}$ also include some vibrationnal cooling signature with a time constant $\tau_{2}$ of $500 \mathrm{fs}$,giving an overall apparent $\tau$ for reaching the final HS state of $350 \mathrm{fs}$ (Fig. 5and 6).

The femtosecond optical studiesreported for (3) and (4) shown in Fig. 5clead to similar conclusion: a transient absorption peak appears for both polymorphs due to a LMCT state. We show the time dependent optical transmissionat $600 \mathrm{~nm}$ between negative and positive delays, varying in opposite directions for the two polymorphs ( $\Delta \mathrm{T}$ is shown for (3) and $-\Delta \mathrm{T}$ for (4)) between LS and HS states, confirm the formation of HS states. Here again we observe for both compounds, an exponential-like population of the HS state, which proceeds from the LMCT state with a 300 fs time constant.

The initial step of LS-HS conversion in solids is therefore equally fast as the one observed for other spin-crossover molecules in solution. This is due to the local nature of structural trapping of the electronic excited state. But a very important aspect of SCO solidsresides in revealingcooperativity or non-linear response of such systems to light excitation, which indeed is the case for some molecular materials $[5,20,67,68,69]$. The response of a single crystal (1) to different excitation fluencies, during the ultrafast photoswitchingstep performed at $140 \mathrm{~K}$ isshown in Fig 7a. The fraction of molecules photo-switched to the HS state, $X_{H S}{ }^{h v}$, was estimated from $\triangle \mathrm{OD}$ on the plateau atpicosecond timescale. It shows a clear linear dependence with the excitation fluency $F$. In addition, a fluency $F=100 \mu \mathrm{J} / \mathrm{mm}^{2}$ in the probed volume corresponds typically to $3( \pm 1)$ photons per 100 
Edited May 24

molecules. As the fraction of these molecules converted from LS to HS state is $2.5(0.5) \%$, it comes out that the efficiency of the process is very high (nearly every absorbed photon switches one molecule from LS to HS states). However, we could not detect any cooperative or self-amplification response during the course of ultrafast photoswitchingdynamics, despite the fact that this crystal shows a strongly cooperative behavior at thermal equilibrium. This linear response to excitation

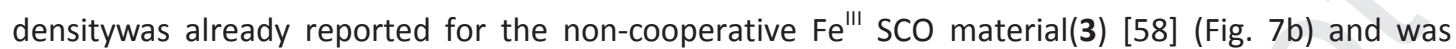
proportional to the fraction of molecules in the LS state prior to photo-excitation $[55,60]$. All these observations underline the fact thatthe photoswitching,which occurs within less than 1 ps,can be regarded as independent local molecular eventsboth for spin-crossover and spin-transition single crystals as none of them show self-amplification on the ps timescale.

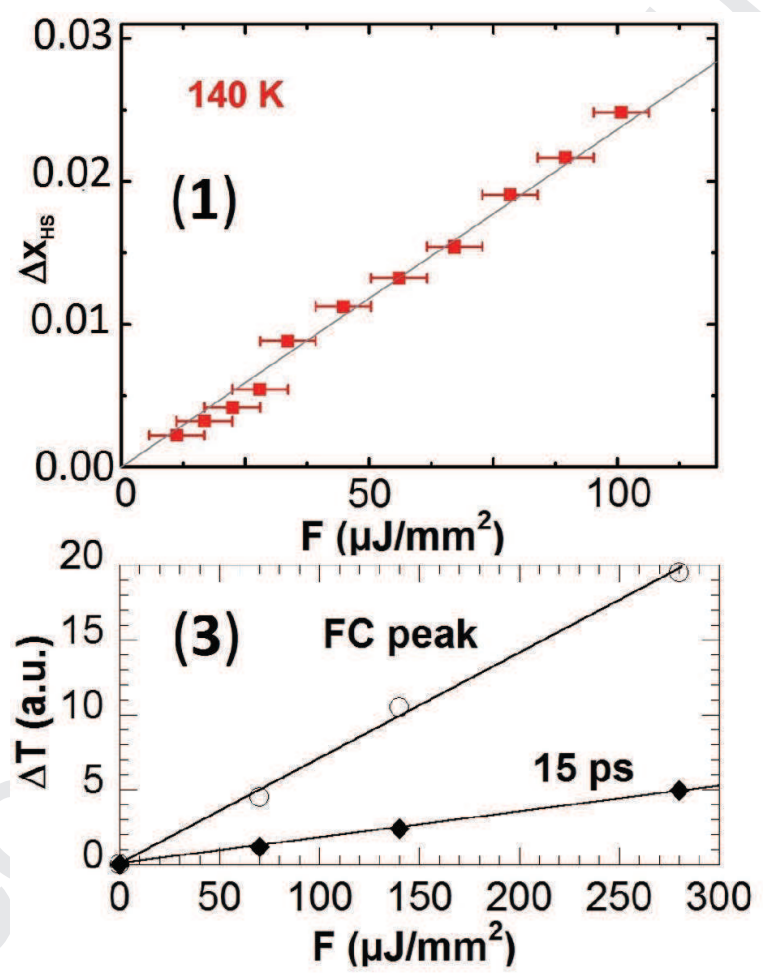

Fig.7.Fluency dependence of the fraction of molecules photo-converted to the HS state at $140 \mathrm{Kfor}(\mathbf{1})$ after irradiation at $850 \mathrm{~nm}$ of a $20 \mu \mathrm{m}$ thick single crystal, and of the photo-response on the LMCT Franck-Condon peak and transmission variation at 15 ps for (3).Part of the figure was reproduced from ref. [58], with permission of the copyright holders. 
Edited May 24

\section{Spin-state switching driven by lattice expansion and heating}

After the photoswitching process discussed above, a complex out-of-equilibrium dynamics takes place, involving consecutive processes. Because of the local photo-switching, an internal pressure sets in, resulting from the molecular swelling (as Fe-ligand bonds expand). Time-resolved Xray absorption spectroscopy of SCO molecules in solution and fs $\mathrm{x}$-ray diffraction experiments in crystals also demonstrated that the Fe-ligand bonds elongate on the $\approx 200 \mathrm{fs}$ timescale $[70,71,72,73]$. In addition, this photoswitching induces lattice heating as every photo-excited molecule releases energy through electron-phonon coupling and then phonon-phonon relaxation processes.Both effects drive lattice expansion, which was observed to occur after $\approx 50$ ns by time-resolved $x$-ray diffraction in (4) $[57,58]$ and in (3) $[21,55,56]$ as shown in Fig. 8 c. This crystal expansion leaves space for other molecules to swell, promoting additional molecules into the HS state, as observed both by time-resolved x-ray diffraction (Fig. 8a) and optical spectroscopy (Fig. 1). However, this macroscopic expansion is not instantaneous but rather limited by the propagation of elastic strain in the crystal $[57,58]$. Finally, the heating of the lattice by the laser flash, associated with an important increase of the Debye-Waller factor observed by x-ray diffraction (Fig. 1c), is accompanied by the thermal population of the HS state, which occurs on the $\mu$ s regime.

Fig. 8. Time dependence of the HS fraction (a), <Fe-N $>$ bond length (b), and of the lattice parameter $a(c)$ deduced from $x$-ray diffraction data for (3). Figureswerereproduced from ref. [22,56], with permission of the copyright holders.

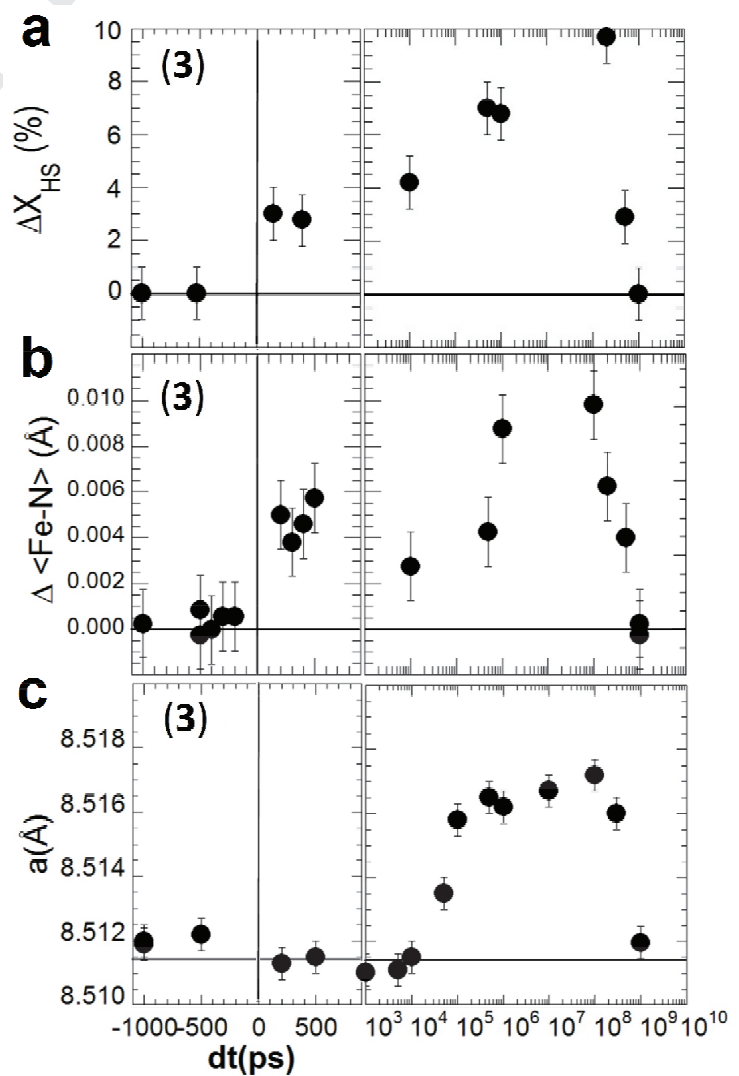


Edited May 24

\subsection{Results}

As discussed in the introduction, it is interesting to compare these slower elastic and thermal spin-state conversion in the different compounds and we adopted the strategy described in ref [55] (see experimental section hereafter). Fig 9 compares the photoresponse of the different single crystals (1), (3) and (4) of similar sizes on a time domain spanning from ps to ms. In these 3 systems, the following three-step process is clearly evidenced:

- the localspin state photoswitching, after the transient LMCT peak,corresponds withthe first increase of the HS fraction of few percents (step "hv"in Fig 9), which occurs within less than 1 ps, as shown in Fig. 1.

- the elastic switching, which gives thesecond increase (step "el" in Fig.9)in the 10-100 ns time scale. - the thermal population of the HS state (step "th" in Fig.9), with the third increase at $\mu$ s time scale.
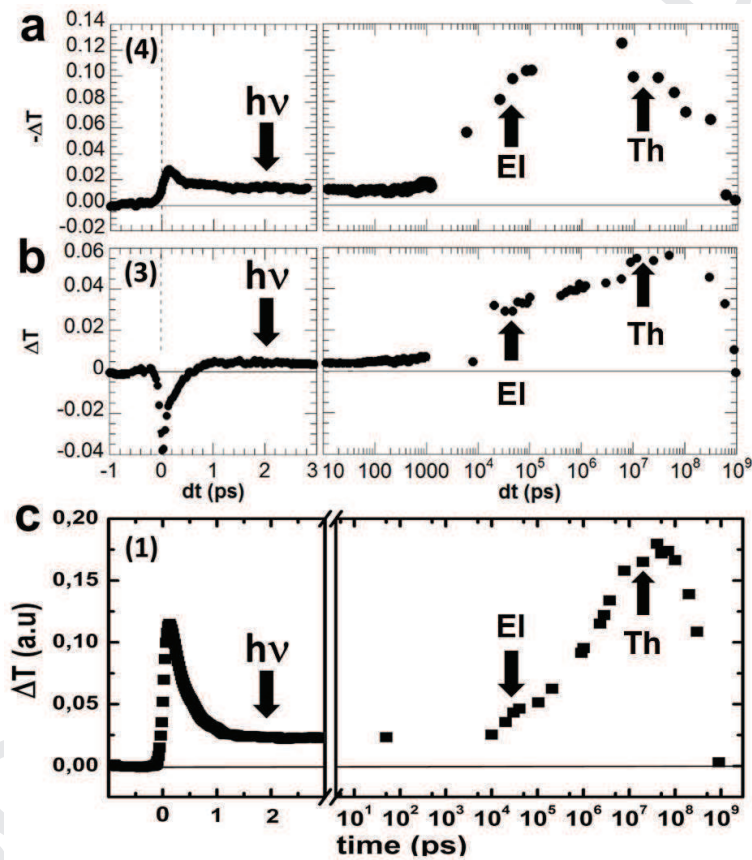

Fig. 9. Time dependence over several temporal scales of $\Delta \mathrm{T}$ for $(\mathbf{3}, \mathrm{b})$ and $-\Delta \mathrm{T}$ for $(\mathbf{4}, \mathrm{a})$ at $600 \mathrm{~nm}$ and $(\mathbf{1}, \mathrm{c})$ at $550 \mathrm{~nm}$. The figureswerepartly reproduced from ref. [58], with permission of the copyright holders."hv", "el" and"th" denote respectively the photo-induced, elastic and thermal steps. 
Edited May 24
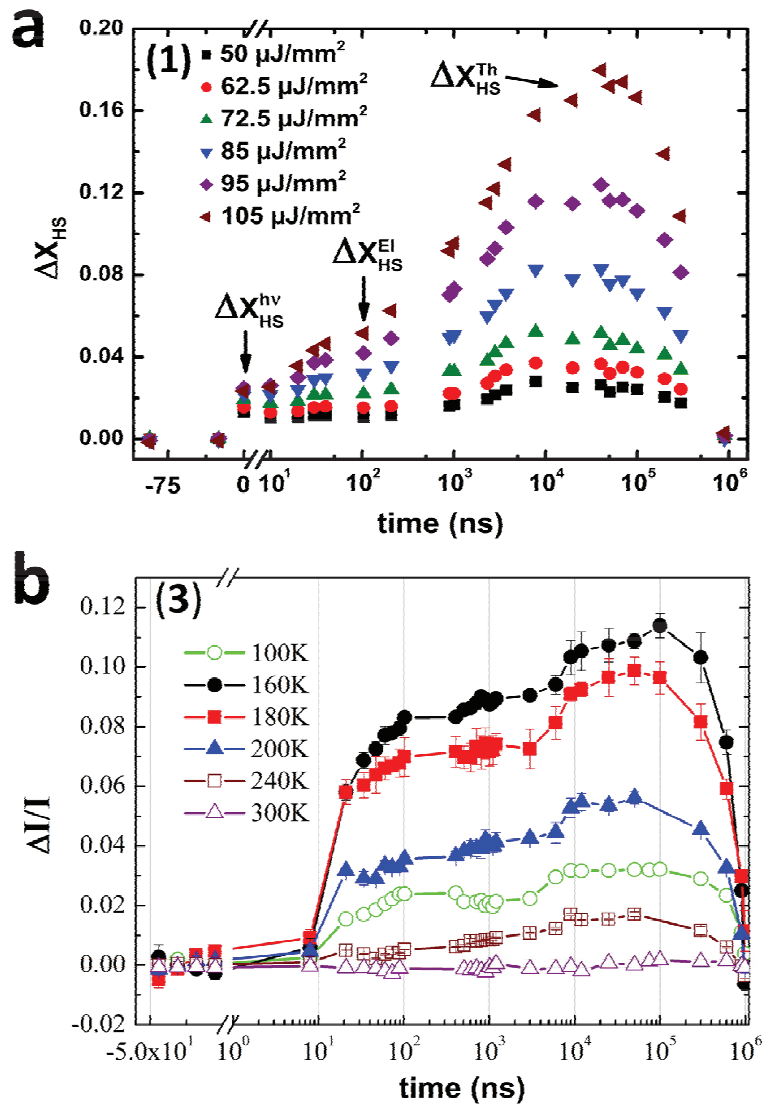

Fig.10.(a) Photo-excited fraction of HS molecules at $140 \mathrm{~K}$ as a function of pump energyfor (1) revealing the 3 steps of photoinduced $\left(\Delta X_{H S}{ }^{h v}\right)$, elastic $\left(\Delta X_{H S}{ }^{E I}\right)$ and thermal $\left(\Delta X_{H S}{ }^{T h}\right)$ nature and (b) photo-response of (3) for different temperatures. Figureswerepartly reproduced from ref. [55], with permission of the copyright holders.

Fig 10 shows how $\Delta X_{H S}$ evolves after fs laser excitation. The first time point measured at positive delay after laser excitation is 10 ps, when the local photoswitching dynamics towards the HS state presented in Fig. 4 is already complete. At this stage a fraction $\Delta X_{H S}{ }^{h v}$ of molecules are converted from LS to HS and we note $\Delta X_{H S}{ }^{E I}$ and $\Delta X_{H S}{ }^{T h}$ the HS conversion on the elastic and thermal steps respectively.On the one hand, we analyze in (1) the effect of excitation density and on the other hand the effect of temperature in (3).

For (3) the occurrence of significant thermal switching at the microsecond timescale is observed with a maximum response in the $160-180 \mathrm{~K}$ range. This results from two main effects described in detail in [55]: the temperature dependence of heat capacity, $C_{p}(T)$, and of $X_{L S}(T)$ the initial fraction of molecules in the LS state at a given temperature T. The optical energy absorbed by the crystal is redistributed over phonons during the relaxation process from the LMCT states to the lower lying HS state. This heat causes temperature increase $\Delta T$ on the macroscopic scale of the crystal, which occurs on $\mu$ s time scale and is limited by heat diffusivity. After this global heating, the HS fraction reaches a transient equilibrium value $\mathrm{X}_{\mathrm{HS}}(\mathrm{T}+\Delta \mathrm{T})$. But the amount of absorbed optical energy is proportional to 
Edited May 24

$X_{L S}(T)$, the initial fraction of LS molecules, which is temperature dependent for (3) asit decreases in above 160 Kwith the gradual thermal conversion from LS to HS states. Therefore the temperature jump $\Delta \mathrm{T}$ becomes smaller when $\mathrm{X}_{\mathrm{LS}}$ decreases. This explains whythe thermal conversion is more efficient at the beginning of the thermal crossover than at the crossover temperature.

For (1), upon the thermal step, the HS population is alsohigherthan upon the photo-switching step.However, a complete conversion could not be reached by increasing the pump energy, due to sample damage. For this reason, the maximum conversion for (1) on the photoswitching step is $\Delta X_{H S}{ }^{h v} \approx 2.5 \%$ and the corresponding HS fraction thermally populated at $50 \mu \mathrm{s}$ is $\Delta X_{H S}{ }^{T h} \approx 18 \%$. The experimental values of $\Delta X_{H S}{ }^{h v}=0,007$ obtained for [(TPA)Fe(TCC)]PF with $40 \mu \mathrm{J} / \mathrm{mm}^{2}$ pulse, and $\Delta X_{H S}{ }^{h v}=$ 0.025 obtained for [Fe(3-MeO-SalEen $)_{2}$ ] $\mathrm{PF}_{6}$ with $105 \mu \mathrm{J} / \mathrm{mm}^{2}$ pulse are quite consistent and scale well with the excitation densities and the slight differences may come from the absolute OD (extinction coefficients, crystal thickness) and the uncertainties mentioned above.

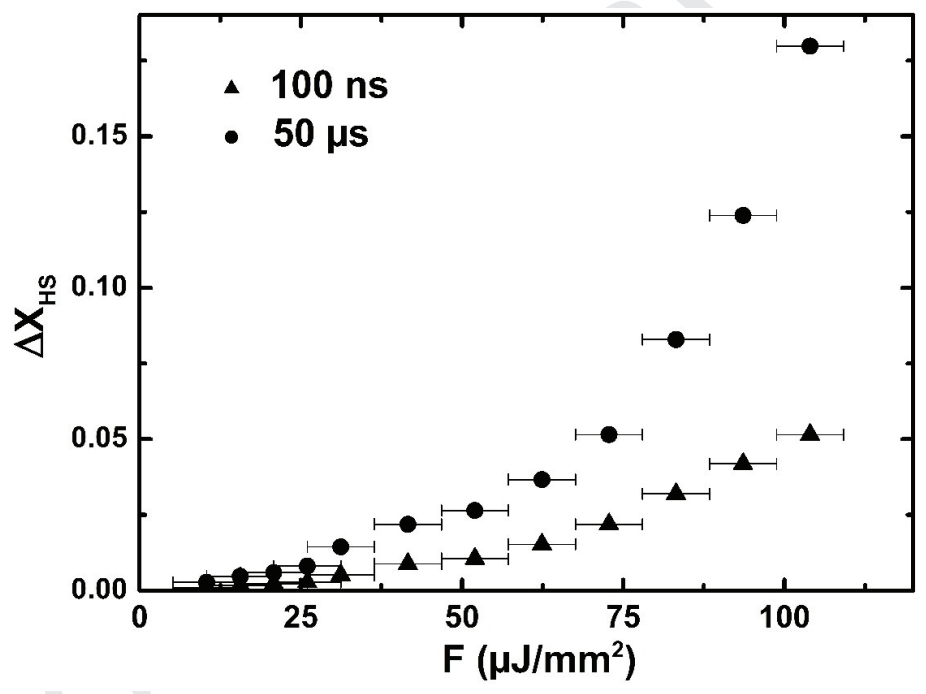

Fig.11.Evolution of the fraction of HS molecules on the elastic (100 ns) and thermal steps(50 $\mu \mathrm{s})$ with the laser fluence, measured on (1) at $\mathrm{T}=140 \mathrm{~K}$.

Fig. 11 shows how $\Delta X_{H S}{ }^{E l}$ and $\Delta X_{H S}{ }^{T h}$, the fraction of molecules populating the HS state on the elastic (100 ns) and thermal(50 $\mu \mathrm{s})$ steps, change with respect to the excitation density for (1). This is a clear proof of the non-linear character of the elastic and thermal switching with the optical energy deposited on the crystal.The time dependence of the thermal HS population process $\Delta X_{H S}{ }^{T h}$ for (1) showedin Fig. 12follows anexponential like law. The different fits (continuous lines) performed for different excitation densities give an average value of $\approx 2.3(5) \mu$ s time constant. For the data shown in Fig. 12 with an initial temperature of $140 \mathrm{~K}$, a temperature jump of $20 \mathrm{~K}$ for $105 \mu \mathrm{J} / \mathrm{mm}^{2}$ fluency will correspond with a transient temperature of $160 \mathrm{~K}$, whereas a $52.5 \mu \mathrm{J} / \mathrm{mm}^{2}$ fluency will correspond 
Edited May 24

with a temperature jump of $10 \mathrm{~K}$ and transient temperature of $150 \mathrm{~K}[55,58]$. Given the accuracy of our data and the fact that the rate constants of the LS $\leftrightarrow$ HS equilibrium depend on temperature, this temperature change is not high enough to allow the detection of variations in the time constant.

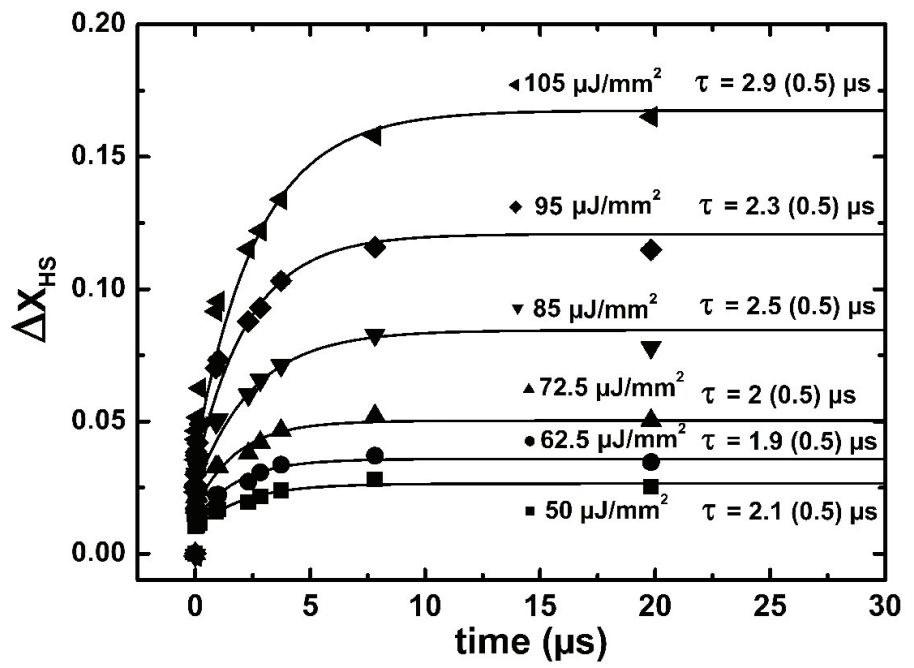

Fig.12. Thermal population of the transient HS state towards $\Delta X_{H S}{ }^{T h}$ for (1).

\subsection{Discussion}

The data presented above mainly underline threeeffects in solids: the photoswitching process, the elastic step and the thermal population of the HS state. However, the HS state is not stable within the experimental condition set(140 K, ambient pressure) and we also observe the $\mathrm{HS} \rightarrow$ LS relaxation.The kinetic of $\mathrm{HS} \rightarrow$ LS relaxation and LS/HS out-of-equilibrium dynamics was already investigated in solution (around ambient temperature), using diverse methods including laser-flash photolysis,[74,75] Raman temperature jump techniques,[76] and ultrasonic relaxation[77].These studies mainly focused on the HS $\rightarrow$ LS relaxation process, providing lifetime of the transient HS state of the order of 10-1000 ns ( $\mathrm{K}_{\mathrm{HL}}$ rate constants on the order of $\left.10^{6}-10^{8} \mathrm{~s}^{-1}\right)$. In the solid state, this relaxation can be very slow at low temperature and a broad distribution of SCO rate constants appears, which are sample and temperature dependent and can span from $10^{-14}$ to $10^{9} \mathrm{~s}^{-}$ ${ }^{1}[27,37,64]$.

Fig. 13shows the local HS $\rightarrow$ LS relaxation process of the photo-switched molecules in (1), observed on the ns time scale. For analyzing the relaxation dynamics we used an exponential fit, whichyields $\approx 300$ ps time constant $\left(\mathrm{k}_{\mathrm{HL}} \approx 310^{9} \mathrm{~s}^{-1}\right)$. It can be compared to the results obtained by the laserflash photolysis technique developed by McGarvey and Lawthers to directly measure the rate at which spin-crossover complexes interconvert between the HS and LS states in solution[74].This relaxation process is of intramolecular nature unlike the one shown in Fig. 14 related to the 
Edited May 24

macroscopic $300 \mu$ s relaxation dynamics of the crystal, which results from heating process following homogeneous/bulk excitation. The excess optical energy deposited on few molecules close to the surface of crystal (heterogeneous excitation) is converted to heat, which allows for a thermal population of the HS state, as the resulting temperature jump $\Delta T$ modifies the LS/HS equilibrium. Such population decays on the ns time scale. Nevertheless (as shown in the case of Fig. 14), the macroscopic and homogeneous temperature increase of the crystals is limited by heat diffusivity and thus occurs only on the $\mu$ s timescale[21,56] with the apparent $2.3 \pm 0.5 \mu$ s time constant for populating HS state.

Hauser explained that the LS to HS conversion may be regarded as tunneling for thermally populated levels LS vibrational states having large Franck Condon factors with the corresponding vibrational levels of HSstate [67]. There are two parameters that may explain the non-linear population of the HS state with respect to the optical energy absorbed by the crystal (Fig. 11). The first one is that the overlap between the vibrational levels of HS and LS states is higher when temperature is higher. The other one is that in cooperative systems the relative position in energy of the HS and LS potential depends on the HS fraction and therefore the increase of tunneling efficiency may be non-linear with the increase of the transient temperature. Finally, even though the laser penetration depth is in the range of crystal thickness, there may exist a gradient of deposited energy and it was also demonstrated that it takes $\mu$ s for the crystal to reach a homogeneous transient hot state[58]. This slow heat diffusivity may be the limiting factor for observing the thermal population of the HS state.As a transient temperature is reached in the crystal on the $50 \mu$ simescale, the new LS/HS equilibrium is reached, with a transient thermally populated HS fraction as high as $\Delta X_{H S}{ }^{\text {Th }} \approx 18$ \%. For such laser excitation densities, the temperature jump $\Delta \mathrm{T}$ is in the $10-30 \mathrm{~K}$ range[55,57]. Therefore, the slower $300 \mu \mathrm{HS} \rightarrow$ LS relaxation process observed in Fig. 14is due to the recovery by the crystal of the initial temperature at equilibriumand this process is limited by the heat exchange between the sample and the cryostat as already underlined by Enachescu and Lorenc $[21,28]$. 
Edited May 24

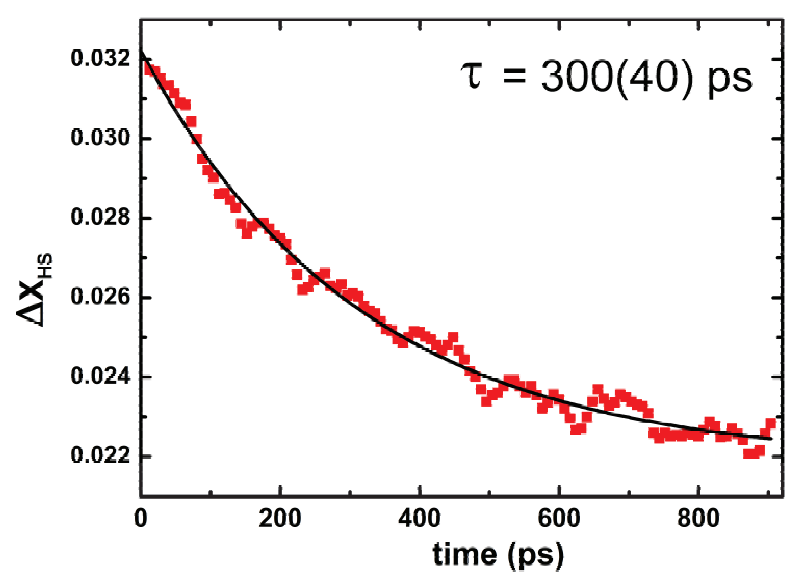

Fig.13. Molecular HS $\rightarrow$ LS relaxation switching dynamics in the ns range for $120 \mu \mathrm{J} / \mathrm{mm}^{2}$ excitation density at $140 \mathrm{~K}$ for (1)

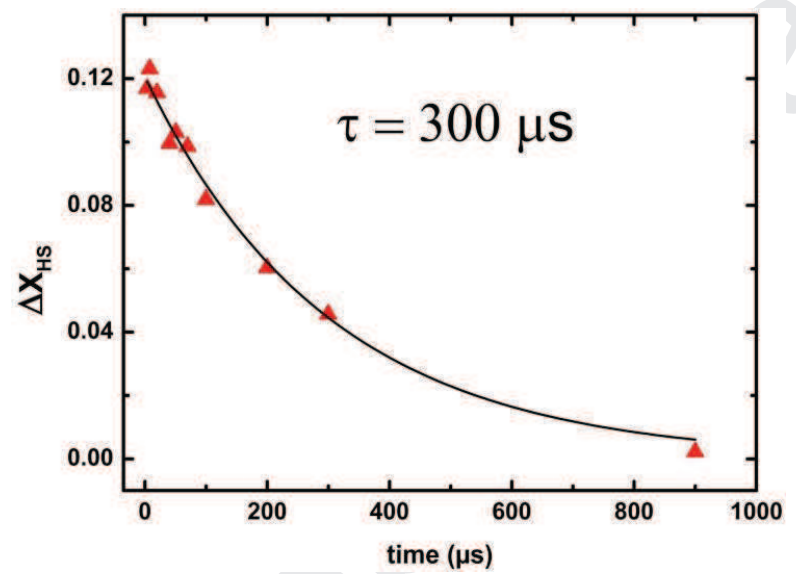

Fig.14. Macroscopic HS $\rightarrow$ LS relaxation due to sample thermalization at $140 \mathrm{~K}\left(90 \mu \mathrm{J} / \mathrm{mm}^{2}\right)$ for (1)

\subsection{Comparison between strongly and weakly cooperative crystals}

It is interesting to compare the out-of-equilibrium dynamics following photoswitching triggered by ultra-short light pulseobtained in a cooperative crystal showing a first-order phase transitionto the ones reported in weakly cooperative crystals (Fig. 10).

Regarding the ultrafast LS-to-HS photoswitching step, the dynamics are similar: it occurs within $\approx 200 \mathrm{fs}$ and the fraction of molecules photo-convertedto the HS state changes linearly with the excitation density both for the present cooperative material (Fig. 7) and for weakly cooperative system.This local molecular transformation is similar to the one observed for molecules in solution. 
Edited May 24

Regarding the elastic step, in weakly cooperative systems (Fig. 1), the internal pressure induced by the local process due to the "swelling" of molecules and lattice heating is ensued by volume expansion. During this elastic step the fraction of HS molecules strongly increases and becomes six times higher than the initial fraction of photo-switched molecules in the weakly cooperative solids (3) and (4) (Fig. 9). The amplitude of the elastic step in terms of HS conversion also depends on the difference between the crossover-and the working-point temperature,so the strong response in Fig. 1 is obtained in the vicinity of the crossover[55,60]. The elastic step results from the negative pressure (in the order of 300 bars [60]) due to the photoswitching process inducing both "swelling" of molecules and lattice heating. The mechanism is schematically represented in the left part of Fig. 15 with a $(P, T)$ phase diagram. The experiment starts at a given temperature and ambient pressure marked by the white point, in the vicinity of the LS-HS crossover. On the timescale of the elastic step the HS state population is not thermally equilibrated as the propagation of heat requires $\mu$ s delay. Therefore the temperature can be considered as constant for simplicity and thus the discontinuous white line represents the transformation path. The release of internal pressure $\Delta \mathrm{P}$, corresponding to a path towards negative pressure (Fig. 15) from a mainly LS (blue) state,favors an increase of $\mathrm{HS}$ (red) fraction by $\Delta X_{H S}{ }^{E I}$. For the cooperative system presented here, the release of internal pressure $\Delta \mathrm{P}$ is not high enough for reaching the HS phase. This may be possible with higher excitation density (associated with larger $\Delta \mathrm{P}$ ) or by performing the experiment at higher temperature, but exploring either of these cases is prohibited by irreversible damage (cracking) of the crystals.

Finally, on longer timescale ( $50 \mu \mathrm{s})$ the system settles toa transient equilibrium state with a transient higher temperature, corresponding to a new LS/HS equilibrium given by $X_{H S}(T+\Delta T)$. In the case of a cooperative material, this equilibrium is strongly modified in the vicinity of the phase diagram and the HS state is thermally populatedwith significant molecular fraction. In the case of (1) at $140 \mathrm{~K}$, a $\Delta \mathrm{T}=22 \mathrm{~K}$ temperature jump is sufficient to give rise to a complete conversion because of the abrupt LS-HS conversion at $162 \mathrm{~K}$ and this explains why the thermal response strongly increases with excitation density (Fig. 11). In the case of (3) and (4), a $20 \mathrm{~K}$ temperature jump can only thermally populate a small fraction of HS state because of the more gradual thermal conversion (Fig. 2). At $140 \mathrm{~K}$ temperature jump larger than $100 \mathrm{~K}$ is required for reaching $80 \%$ conversion. 
Edited May 24

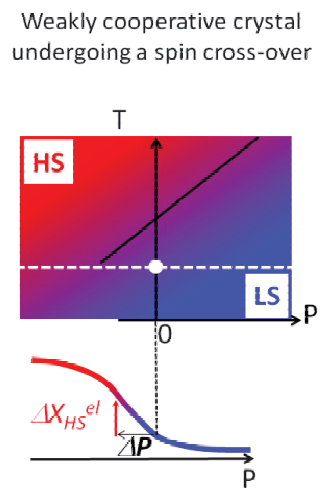

Strongly cooperative crystal with $1^{\text {st }}$ order spin transition

Fig. 15. The $(P, T)$ phase diagram between LS (blue) and HS (red) regions, for weakly (left) and strongly (right) cooperative crystals. In the vicinity of the crossover (left) a negative pressure $\Delta P$ drives an increase of HS fraction by $\Delta X_{H S}{ }^{e l}$. For a crystal with first order transition (right) this is not possible if $\Delta P$ is too small.

\section{Conclusion}

Molecular multistability in solution and in solids allows controlling molecular states by different stimuli and in particularby light excitation. The local molecular photoswitching in solids is very similar to that reported for molecules in solution, and even for the so-called cooperative solids we could not detect self-amplification process on the picosecond time scale. The concerted response of molecules in solids made it possible to identify two other mechanisms driving spin-state switching. One of elastic nature and one of thermal nature. The temperature jump resulting from laser excitation can give rise to a strong response in cooperative systems, which show discontinuous conversion at thermal equilibrium, but this response is more limited in systems showing more gradual response. These results underline the fact that the crystal is an active medium, which can give rise to self-amplification. While the process caused by temperature jump looks to some extent similar to the kinetics in solution, the role of elastic-driven transition is specific to the solid and needs to be further investigated.

\section{Experimental section}

The experimental details regarding already published material can be found in [62] for (1), [53] for (2), $[21,55,56,58]$ for $(3)$ and $[57,58]$ for $(4)$. The optical pump-probe experiments were configured intransmission geometry with quasi-collinear configuration.The complementary results presented here for (1) used the set-up described in [55], combining amechanical translation stage to adjust the optical path difference for sub-ns measurements and the synchronization of two femtosecond 
Edited May 24

amplifiers for $10 \mathrm{~ns}$-ms delays. In the new measurements on (1), the pump wavelength was set to 850 $\mathrm{nm}$ on a LMCT band where it efficiently induces LS-to-HS transition (Fig 4). Single-wavelength transmission measurements at 550 and $760 \mathrm{~nm}$ probed the resulting LS-to-HS photoswitching dynamics by OD change, with an overall instrument response function (IRF) of $\approx 140 \mathrm{fs}$. In first order approximation, it is possible to extract $\Delta \mathrm{X}_{\mathrm{HS}}$ from $\Delta \mathrm{OD}$, if the absolute change of OD between $\mathrm{HS}$ and LS is known $\left(O D_{H S}-O D_{L S}\right)$ :

$\Delta X_{H S}(t)=\frac{\Delta O D(t)}{O D_{H S}-O D_{L S}}$.

Experiments were performed on single crystals with typical dimensions of $(200 \pm 50) \times(300 \pm 50) \times$ $(20 \pm 5) \mu \mathrm{m}^{3}$. Both pump and probe light were parallel to the long crystal axis $\boldsymbol{a}$, for which the penetration depth is maximal. The spot size of the pump beam had a diameter of $150 \mu \mathrm{m}$ and theone of the probe was $80 \mu \mathrm{m}$ to ensure the excitation homogeneity of the analyzed volume. The experiments were performed in the pure LS phase at $120 \mathrm{~K}$ and $140 \mathrm{~K}$, far enough from the thermal transition temperature to avoid residual laser heating effects and high enough to ensure lifetime of the photoinduced HS state shorter than $1 \mathrm{~ms}$ required for performing stroboscopic pump-probe measurements.Crystals were cooled down with a liquid nitrogen cryostream. Thenanocrystals samples $(2)(950 \pm 150) \times(270 \pm 40) \times(35 \pm 7) \mathrm{nm}^{3}$ were dispersed in a transparent PVP matrix. For (3), the typical sample dimensions are $(400 \pm 50) \times(150 \pm 50) \times(20 \pm 5) \mu \mathrm{m}^{3}$.For $(4)$, the typical sample dimensions are $(300 \pm 50) \times(200 \pm 50) \times(15 \pm 5) \mu^{3}$.

\section{Acknowledgements}

This work was supported by the InstitutUniversitaire de France, Rennes Métropole, Région Bretagne (CREATE 4146), the ANR (ANR-13-BS04-0002) and Europe (FEDER).

\section{References:}

[1] A. H. Zewail, Angew. Chem. Int. Ed. 112 (2000) 2688.

[2] J.H. Lee, M. Wulff, S. Bratos, J. Petersen, L.Guérin, J.C. Leiknman J.C., M. Cammarata, Q.Y. Kong, J. Kim, K. Moller, H. Ihee, J. Am. Chem. Soc. 135 (2013) 3255.

[3] K. Haldrup, T. Harlang, M. Christensen, A. Dohn, T. Brandt van Driel, K. Skov Kjær, N. Harrit, J. Vibenholt, L. Guerin, M. Wulff , M. M. Nielsen, Inorg. Chem. 50 (2011) 9329.

[4] K. Nasu, Photoinduced phase transitions , Ed. World Scientist, Singapore, 2004.

[5]. S. Koshihara\& M. Kuwata-Gonokami Eds. Special Topics in J. Phys. Soc. Jpn. 75 (2006) 011001.

[6] M. Kobayashi, S. Masaoka, K. Sakai, Angew. Chem. Int. Ed. 51 (2012) 7431. 
Edited May 24

[7]A. A. Bakulin, A. Rao, V. G. Pavelyev, P. H. M. van Loosdrecht, M. S. Pshenichnikov, D. Niedzialek, J. Cornil, D. Beljonne, R. H. Friend, Science335 (2012) 1340.

[8] C. D'amico, M. Lorenc, E. Collet, K.A. Green, K. Costuas, O. Mongin, M. Blanchard-Desce, F. Paul, J. Phys. Chem. C1163727 (2012) 3719.

[9] M. Iwamura, H. Watanabe, K. Ishii, S. Takeuchi, T. Tahara, J. Am. Chem. Soc. 133 (2011) 7728.

[10] Y. Suffren, D. Zare, S.V. Eliseeva, L. Guénée, H. Nozary, T. Lathion, L. Aboshyan-Sorgho, S. Petoud, A. Hauser, C. Piguet, J. Phys. Chem. C 117 (2013) 26957.

[11] F. Messina, M. Premont-Schwarz, O. Braem, D. Xiao, V. S. Batista, E.T.J. Nibbering, M. Chergui,Angew. Chem. Int. Ed. 52 (2013) 6871.

[12] Y. Zhang, D. Li, R. Clérac, M. Kalisz, C. Mathonière, S, M. Holmes, Angew. Chem. Int. Ed. 49 (2010) 3752.

[13] H. Jean-Ruel, R.R. Cooney, M. Gao, C. Lu, M.A. Kochman, C.A. Morrison, R. J. D. Miller,J. Phys. Chem. A, 115 (2011) 13158.

[14] A. Bousseksou, G. Molnar, L. Salmon, W. Nicolazzi, Chem. Soc. Rev. 40 (2011) 3313.

[15] H. Svendsen, J. Overgaard, M. Chevallier, E. Collet, B.B. Iversen, Ang. Chem. Int. Ed. 48 (2009) 2780.

[16] S. Ohkoshi, K. Imoto, Y. Tsunobuchi, S. Takano, H. Tokoro, Nature Chem. 3 (2011) 564.

[17] L. Catala, D. Brinzei, Y. Prado, A. Gloter, O. Stéphan, G. Rogez, T. Mallah, Angew. Chem. Int. Ed. 48 (2009) 183.

[18] T. Ishikawa, N. Fukazawa, Y. Matsubara, R. Nakajima, K. Onda, Y. Okimoto, S. Koshihara, M. Lorenc, E. Collet, M. Tamura, R. Kato, Phys. Rev. B. 80 (2009) 115108.

[19] B. Siwick, E. Collet. Nature, 496 (2013) 306.

[20] M. Gao, C. Lu,H. Jean-Ruel, L. C. Liu, A. Marx, K. Onda, S. Koshihara, Y. Nakano, X. Shao, T. Hiramatsu, G. Saito, H. Yamochi, R. R. Cooney, G. Moriena, G. Sciaini, R.J.D. Miller, Nature 496 (2013) 343.

[21] M. Lorenc, J. Hébert, N. Moisan, E. Trzop, M. Servol, M. Buron-Le Cointe, H. Cailleau, M. L. Boillot, E. Pontecorvo, M. Wulff, S. Koshihara, E. Collet, Phys. Rev. Lett. 103 (2009) 028301.

[22] D. Boschetto, E. G. Gamaly, A. V. Rode, B. Luther-Davis, D. Glijer, T. Garl, O. Albert, A. Rousse, J. Etchepare, Phys. Rev. Lett. 100 (2008) 027404.

[23] Y. Okimoto, T. Miyata, M.S. Endo, M. Kurashima, K. Onda, T. Ishikawa, S. Koshihara, M. Lorenc, E. Collet, H. Cailleau, T. Arima, Phys. Rev. B, 84 (2011) 121102.

[24]H. Uemura, H. Okamoto. Phys. Rev. Lett. 105 (2010) 258302.

[25] Y. Kawakami, S. Iwai, T. Fukatsu, M. Miura, N. Yoneyama, T. Sasaki, N. Kobayashi, Phys. Rev. Lett. 103 (2009) 066403.

[26] S. Decurtins, P. Gütlich, C. P. Köhler, H. Spiering, A. Hauser, Chem. Phys. Lett. 105 (1984) 1.

[27]Spin-Crossover Materials: Properties and Applications (Ed. M. A. Halcrow), John Wiley \& Sons, 2013.

[28] I. Krivokapic, P. Chakraborty, R. Bronisz, C. Enachescu, A. Hauser. Angew. Chem. Int. Ed. 49 (2010) 85098512.

[29] S. Cobo, D. Ostrovskii, S. Bonhommeau, L. Vendier, G. Molnar, L. Salmon, K. Tanaka, A. Bousseksou, J. Am. Chem. Soc. 130 (2008) 9019.

[30] A. Cannizzo, C.J. Milne, C. Consani, W. Gawelda, Ch. Bressler, F. van Mourik, M. Chergui, Coord. Chem. Rev. 254 (2010)2677.

[31] J.J. McGarvey, I. Lawthers, K. Heremans, H. Toftlund. J. Chem. Soc., Chem. Commun. (1984) 1575.

[32] M. Khalil, M.M. Marcus, A.L. Smeigh, J.K. McCusker, H.H.W. Chong, R.W. Schoenlein, J. Phys. Chem. A. 110 (2006) 38.

[33] A.L. Smeigh, M. Creelman, R.A. Mathies, J.K. McCusker, J. Am. Chem. Soc. 130 (2008) 14105. 
Edited May 24

[34] W. Gawelda, A. Cannizzo, V.T. Pham, F. van Mourik, C. Bressler, M. Chergui, J. Am. Chem. Soc. 129 (2007) 8199.

[35] M.M.N. Wolf, R. Groß, C. Schumann, J.A. Wolny, V. Schünemann, A. Døssing, H. Paulsen, J.J. McGarvey, R. Diller, Phys. Chem. Chem. Phys. 10 (2008) 4264.

[36] M. Chergui , in: M. A. Halcrow (Eds.), Spin-crossover Materials, Wiley, West Sussex, 2013, 405-489.

[37]C. Brady, H. Toftlund, J.J. McGarvey, J.K. McCusker, D.N. Hendrickson, in: P. Gütlich, H.A. Goodwin (Eds.), Spin-crossover in Transition Metal Compounds, vol. III, Springer, Berlin, 2004, p. 1, Top. Curr. Chem., 235.

[38] C. Consani, M. Prémont-Schwarz, A. Elnahhas, C. Bressler, F. van Mourik, A. Cannizzo,M. Chergui, Angew. Chem.Int. Ed. 48 (2009) 7184.

[39] J.K. McCusker, K.N. Walde, R.C Dunn, J.D Simon, D. Madge, D.N. Hendrickson, J. Am. Chem. Soc. 114 (1992) 6919.

[40] J.E. Monat, J.K. McCusker,J. Am. Chem. Soc.122 (2000) 4092.

[41] I. Lawthers, J. J. McGarvey, J. Am. Chem. Soc.15 (1984) 106.

[42] N. Huse, H. Cho, K. Hong, L. Jamula, F.M.F. de Groot, T.K. Kim, J.K. McCusker, R.W. Schoenlein,J. Phys. Chem. Lett. 2 (2011) 880.

[43] W. Gawelda, V. T. Pham, M. Benfatto, Y. Zaushitsyn, M. Kaiser, D. Grolimund, S. L. Johnson, R. Abela, A. Hauser, C. Bressler, M. Chergui, Phys. Rev. Lett. 98 (2007) 057401.

[44] S. Nozawa, T. Sato, M. Chollet, K. Ichiyanagi, A. Tomita, H. Fujii, S. I. Adachi, S.Y. Koshihara, J. Am. Chem. Soc. 132 (2010) 61.

[45] H.T. Lemke, C. Bressler, L.X Chen, D.M. Fritz, K.J. Gaffney, A. Galler, W. Gawelda, K. Haldrup, R.W. Hartsock, H. Ihee, J. Kim, K.H. Kim, J.H Lee, M.M. Nielsen, A.B. Stickrath, W. Zhang, D. Zhu, M. Cammarata, J. Phys. Chem. A 117 (2013) 735.

[46] C. Bressler, C. Milne, V. T. Pham, A. El Nahhas, R.M. van der Veen, W. Gawelda, S. Johnson, P. Beaud, D. Grolimund, M. Kaiser, C. Borca, G. Ingold, R. Abela, M. Chergui, Science 323 (2009) 489.

[47] E. A. Juban, A. L. Smeigh, J. E. Monat, J. K. McCusker, Coord. Chem. Rev. 250 (2006) 1783.

[48] N. Huse, T.K. Kim, L. Jamula, J.K. McCusker, F.M. F. de Groot, R.W. Schoenlein, J. Am. Chem. Soc. 132 (2010) 6809.

[49] N. Bréfuel, H. Watanabe, L. Toupet, J. Come, M. Kojima, N. Matsumoto, E. Collet, K. Tanaka, J.P. Tuchagues, Ang. Chem. Int. Ed48 (2009) 9304.

[50] E. Collet, H. Watanabe, N. Bréfuel, L. Palatinus, F. Roudaut, L. Toupet, K. Tanaka, J.P. Tuchagues, P. Fertey, S. Ravy, B. Toudic, H. Cailleau,Phys. Rev. Lett109 (2012) 257206.

[51] M. Buron-Le Cointe, J. Hébert, C. Baldé, N. Moisan1, L. Toupet, P. Guionneau, J.F. Létard, E. Freysz, H. Cailleau, E. Collet, Phys. Rev. B. 85 (2012) 064114.

[52]O. Fouché, J. Degert, G. Jonusauskas, N. Daro, J. F. Létard, E. Freysz, Phys. Chem. Chem. Phys. 12 (2010) 3044.

[53]R. Bertoni, M. Lorenc, A. Tissot, M. Servol, M.-L. Boillot, E. Collet, Angew. Chem. Int. Ed. 51 (2012) 7485.

[54] A. Marino, P. Chakraborty, M. Servol, M. Lorenc, E. Collet, A. Hauser, Angew. Chem. Int. Ed. 2014 doi: 10.1002/anie.201310884

[55] M. Lorenc, C. Balde, W. Kaszub, A. Tissot, Moisan, M. Servol, M. Buron-Le Cointe, H. Cailleau, P. Chasle, P. Czarnecki, M. L. Boillot, E. Collet, Phys. Rev. B. 85 (2012) 054302.

[56] H. Cailleau, M. Lorenc, L. Guérin, M. Servol, E. Collet, M. Buron-Le Cointe, Acta Cryst. A 66 (2010) 189.

[57] E. Collet, M. Lorenc, M. Cammarata, L. Guérin, M. Servol, A. Tissot, M.L. Boillot, H. Cailleau, M. Buron, Chemistry: A European Journal 18 (2012) 2051.

[58] E. Collet, N. Moisan, C. Baldé, R. Bertoni, E. Trzop, C. Laulhé, M. Lorenc, M. Servol, H. Cailleau, A. Tissot, M.L. Boillot, T. Graber, R. Henning, P. Coppens, M. Buron, Phys. Chem. Chem. Phys. 14 (2012) 6192. 
Edited May 24

[59] A. Marino, M. Servol, R. Bertoni, M. Lorenc, C. Mauriac, J.F. Létard, E. Collet, Polyhedron 66 (2013) 123.

[60] W. Kaszub, M. Buron-Le Cointe, M. Lorenc, M. L. Boillot, M. Servol, A. Tissot, L. Guérin, H. Cailleau, E. Collet, Eur. J Inorg. Chem 5 (2013) 992.

[61] E. Collet, M.L. Boillot, J. Hebert, N. Moisan, M. Servol, M. Lorenc, L. Toupet, M. Buron-Le Cointe, A. Tissot, J. Sainton, Acta Cryst. B 65 (2009) 474.

[62] A. Tissot, R. Bertoni, E. Collet, L. Toupet, M.L. Boillot, J. Mat. Chem. 35 (2011) 2333.

[63] M.S. Haddad, M.W. Lunch, W.D. Federer, D.N. Hendrickson, Inorg.Chem. 20 (1981)123.

[64] H. Ando, Y. Nakao, H. Sato, S. Sakaki, J. Phys. Chem. A 111 (2007) 5515.

[65] A. J. Simaan, M.-L. Boillot, R. Carrasco, J. Cano, J.-J. Girerd, T. A. Mattioli, J. Ensling, H. Spiering, P. GütlichChem. Eur. J. 11 (2005) 1779.

[66] A. Tissot, C. Enachescu, M-L. Boillot, 22 (2012) 20451-20457.

[67] A. Hauser in: P. Gütlich, H.A. Goodwin (Eds.), Spin-crossover in Transition Metal Compounds, vol. II, Springer, Berlin, 2004, p. 155, Top. Curr. Chem., 234.

[68] H. Okamoto, Y. Ishige, S. Tanaka, H. Kishida, S. Iwai, Y. Tokura, Phys. Rev. B 70 (2004) 165202.

[69] M. Chollet, L. Guerin, N. Uchida, S. Fuhaya, H. Shimoda, T. Ishikawa, K. Matsuda, T. Hasegawa, A. Ota, H. Yamochi, G. Saito, R. Tazaki, S. Adachi, S. Koshihara, Science 307 (2005) 86.

[70] B.Freyer, F.Zamponi, V. Juvé, J.Stingl, M.Woerner, T.Elsaesser, M.Chergui, J. Chem. Phys. 138 (2013) 144504.

[71]C. Bressler, C. Milne, V.-T. Pham, A. El Nahhas, R. M. van der Veen, W. Gawelda, S. Johnson, P. Beaud, D. Grolimund, M. Kaiser, C. N. Borca, G. Ingold, R. Abela and M. Chergui, Science 323 (2009) 489.

[72]N.Huse, H. Cho, K. Hong, L.Jamula, F. M. F. de Groot, T. K. Kim, J. K. McCusker, R. W. Schoenlein, J. Phys. Chem. Lett. 2(2011),880-884.

[73] H. T. Lemke, C. Bressler, L. X. Chen, D. M. Fritz, K. J. Gaffney, A. Galler, W. Gawelda, K. Haldrup, R. W.Hartsock, H. Ihee, J. Kim, K.-H. Kim, J.-H. Lee, M. M. Nielsen, A. B. Stickrath, W. Zhang, D. Zhu, M. Cammarata, J. Phys. Chem. A 117 (2013) 735-740.

[74] J.J. McGarvey, I. Lawthers, K. Heremans, H. Toflund, Inorg. Chem. 29 (1990) 252.

[75] H. Toflund, Coord. Chem. Rev. 97 (1989) 67.

[76] E.V. Dose, M.A. Hoselton, N. Sutin, M.F. Tweedle, L.J. Wilson, J. Am. Chem. Soc. 100 (1978) 1141.

[77] J.K. Beattie, K.J. McMahon, Austr. J. Chem. 41 (1989) 1315; J.K. Beattie Adv. Inorg. Chem. 1988, 32, 1-53.

[78] J. J. McGarvey, I. J. Lawthers, Chem. Soc., Chem. Commun. (1982) 906. 
-An overview spin-state photo-switching in $\mathrm{Fe}^{\mathrm{III}}$ spin-crossover crystals is provided -Ultrafast optical spectroscopy reveal a sequence of conversion -Lattice expansion and heating induce additional spin-state conversion -The photo-response is linear with excitation density

-The thermal conversion is strong in cooperative materials close to phase transition 